\title{
The herbicide paraquat induces alterations in the elemental and biochemical composition of non-target microalgal species
}

\author{
R. Prado, C. Rioboo, C. Herrero, A. Cid, ${ }^{1}$
}

Chemosphere, Volume 76, Issue 10, September 2009, Pages 1440-1444

Received 31 December 2008, Revised 26 May 2009, Accepted 1 June 2009, Available online 1

July 2009

DOI: 10.1016/j.chemosphere.2009.06.003

\begin{abstract}
Huge quantities of pesticides are dispersed in the environment, affecting non-target organisms. Since paraquat affects the photosynthetic process, the biochemical composition of affected species should be altered. The effect of paraquat on Chlamydomonas moewusii, a freshwater non-target species, was studied. After $48 \mathrm{~h}$ of herbicide exposure, growth rate, dry weight, and chlorophyll $a$ and protein content were affected by paraquat concentrations above $0.05 \mu \mathrm{M}$. C/N ratio was also affected due to a decrease in nitrogen content in the dry biomass, while the carbon content remained constant for all paraquat concentrations assayed. Enzymes involved in nitrogen assimilation were affected by paraquat, being nitrate reductase activity more sensitive to paraquat than nitrite reductase. Based on the results obtained in the present study, paraquat exerts adverse effects upon a common freshwater green microalga, thus the application of this herbicide for weed control must be carried out very carefully, so that any disturbance affecting algae will have severe repercussions on higher trophic levels and on the elemental biogeochemical cycles.
\end{abstract}

\section{Keywords}

Microalga; Herbicide; Toxicity; Nitrogen metabolism

\section{Introduction}

Aquatic environments are often contaminated with numerous organic and inorganic compounds, including herbicides which are among the most widely used toxic chemicals for various purposes in industry, forestry, gardens, agriculture and households (Fatima et al., 2007). As much as ca. $99.7 \%$ of the applied load of pesticides is dispersed in the environment, not reaching their target pests. In this way, pesticides enter into aquatic ecosystems from agricultural runoff or leaching, and as a consequence, have become some of the most frequently occurring organic pollutants in aquatic ecosystems ( Pimentel, 1995 and Ibáñez et

\footnotetext{
${ }^{1}$ Laboratorio de Microbiología, Facultad de Ciencias, Universidad de A Coruña, C/Alejandro de la Sota no 1, 15008 A Coruña, Spain
} 
al., 1996). Pesticides differ from most industrial organic chemicals in that they are brought into the environment with the explicit intention of exerting toxic effects on one or more target organisms. Unfortunately, their toxicity is usually not limited to the location where they are applied, reaching other locations and environmental compartments through various physical transport processes and adversely affecting organisms that happen to be present (Deneer, 2000). Numerous observed effects of pesticides on aquatic biota suggest that these chemicals, at concentrations present in the environment, may have the capability to induce changes at the molecular, cellular and genetic levels in various organisms ( Arkoosh et al., 1998, Tanguy et al., 2005 and Amado et al., 2006).

Algae composing the primary producer level are of initial importance in providing the energy that sustains invertebrates and fish in most aquatic ecosystems. The action of toxic substances on algae is therefore not only important for the organisms themselves, but also for other links in the food chain (De Lorenzo et al., 2002 and Rioboo et al., 2007). In this way, herbicides can affect the structure and function of aquatic communities by altering the species composition of an algal community (Ma et al., 2002).

Paraquat (1,1'-dimethyl-4,4'-bipyridilium dichloride) is a non-selective herbicide widely used to prevent the growth of broad leaf weeds and grasses. This quaternary ammonium compound is a cationic species in aqueous solution and, after application, this chemical can be adsorbed into the soil or transported to the aquatic environment by runoff or leaching (Ibáñez et al., 1996); its mode of action, as a competitive inhibitor of photosynthetic electron transport at PS I level, makes it potentially lethal to a wide variety of non-target species of primary producers, including microalgal species (Franqueira et al., 1999).

The alteration provoked in the photosynthetic process should be correlated with changes in growth parameters and biochemical composition of the paraquat exposed cells. Based on that, the aim of the present study was to determine the potential effect of paraquat on the biochemical and elemental composition of an ubiquitous and amenable to culture freshwater green microalga Chlamydomonas moewusiafter $48 \mathrm{~h}$ of exposure to increasing concentrations of this herbicide.

\section{Materials and methods}

\subsection{Microalgal cultures}

C. moewusii Gerloff (Chlamydomonadaceae) was obtained from the Culture Collection of Algae and Protozoa of Dunstaffnage Marine Laboratory (Scotland, UK) (strain CCAP 11/5B) and was grown on sterile Bristol medium ( Brown et al., 1967), which was supplemented with increasing paraquat concentrations $(0.05,0.1,0.15$ and $0.2 \mu \mathrm{M})$. Paraquat stock solution $(1 \mathrm{mM})$ was prepared by dissolving granulated herbicide paraquat (Sigma; MW: 257.2) in distilled and sterilized water. Cultures without paraquat were also included as a control. 
All cultures were carried out in duplicate in Pyrex glass bottles containing $500 \mathrm{~mL}$ of medium. Initial cell density for each experiment was $4 \times 10^{5}$ cells $\mathrm{mL}^{-1}$. For the assays, cells from a 3-dold culture were used as inoculum. Microalgal cultures were maintained at $18 \pm 1{ }^{\circ} \mathrm{C}$, illuminated with $68.25 \mu \mathrm{mol}$ photon $\mathrm{m}^{-2} \mathrm{~s}^{-1}$, with a dark:light cycle of $12: 12 \mathrm{~h}$, and continuously aerated.

\subsection{Growth measurement}

Growth of microalgal cultures was measured by counting daily culture aliquots in a Coulter Epics XL4 flow cytometer equipped with an argon-ion excitation laser (488 nm). Fluorescence of chlorophyll a was used to exclude non-microalgal particles, and red fluorescence (>645 nm) was used as gate.

Growth rate $(\mu)\left(\mathrm{d}^{-1}\right)$ was calculated using the following formula:

$\mu=\left[\operatorname{In}\left(N_{t}\right)-\operatorname{In}\left(N_{0}\right)\right] / \operatorname{In} 2\left(t-t_{0}\right)$

where $N_{t}$ is the cell density (cells $\mathrm{mL}^{-1}$ ) at time $t(d)$

and $N_{0}$ is the cell density at time 0 .

Growth data were fitted by a non-linear regression with the regression wizard software (SigmaPlot 8.0, SPSS Inc.).

\subsection{Biochemical composition}

Samples for biochemical determinations were always collected at the same time of the light period because biochemical composition of microalgal cells can vary depending on the moment of the light period in which sample is taken (Ganf et al., 1986). Chlorophyll a content was determined spectrophotometrically from $90 \%$ acetone extracts using the formula of Jeffrey and Humphrey (1975).

Hydrosoluble protein content was measured in the crude extract obtained after breaking microalgal cells in an ultrasonic disintegrator. After sonication at $4{ }^{\circ} \mathrm{C}$, the extracts were centrifuged, the pellets discarded and protein content was measured in the supernatant by the dye-binding method (Bradford, 1976).

\subsection{Dry weight and elemental composition}

The dry weight was determined according to Utting (1985). Culture aliquots (10 mL) were filtered through previously dried and weighed Whatman GF/C filters. Thereafter, the filters were dried in an oven at $80^{\circ} \mathrm{C}$ for $72 \mathrm{~h}$.

Samples for elemental composition were taken by centrifugation of aliquots of culture at $3500 \mathrm{rpm}$ and frozen at $-70^{\circ} \mathrm{C}$ prior to lyophilisation for $24 \mathrm{~h}$. Carbon and nitrogen content were obtained with an elemental analyser (Carlo Erba CHNS-O 1108).

\subsection{Nitrate reductase and nitrite reductase activities}


The nitrate and nitrite reductase activities were determined using in situ assay protocols based on the colorimetric determination of nitrite formed after enzymatic reduction of nitrate with NADH as electron donor for the nitrate reductase activity (Barea and Cárdenas, 1975 and Berges and Harrison, 1995), and of nitrite disappeared as a consequence of its reduction with metilviologen in the presence of sodium dithionite for the nitrite reductase activity ( Barea and Cárdenas, 1975). Colorimetric determination of nitrite was carried out according to Snell and Snell (1949) in both enzymatic activity assays.

Enzymatic activity was expressed as specific activity, in units of enzymatic activity per gram of protein, taking into account that one unit of enzymatic activity catalyses the conversion of $1 \mu$ mol of substrate to product per minute.

\subsection{Data analysis}

Since the aim of the present study is to evaluate the effect of paraquat on different parameters, the data obtained after $48 \mathrm{~h}$ of herbicide exposure were statistically analysed by an overall oneway analysis of variance (ANOVA) and, when differences observed respect to the control cultures were significant, the means were compared by multiple-range Duncan test, at a level of significance of $0.05(p<0.05)$.

\section{Results}

\subsection{Growth}

Microalgal growth was used to measure the toxicity of paraquat in a global manner, and the results obtained show that paraquat affected the growth of the freshwater microalga $C$. moewusii ( Table 1). All paraquat concentrations assayed provoked a significant $(p<0.05)$ decrease in the growth rate of this microalga, except for the lowest concentration assayed $(0.05 \mu \mathrm{M})$ which enhanced growth ( Table 1).
Table 1. represented by an asterisk $\left(^{*}\right)$.

\begin{tabular}{ll} 
Paraquat concentrations $(\mu \mathrm{M})$ & $\mu 48 \mathrm{~h}\left(\mathrm{~d}^{-1}\right)$ \\
\hline Control & $0.712 \pm 0.001$ \\
0.05 & $0.728 \pm 0.002^{*}$ \\
0.1 & $0.512 \pm 0.004^{*}$ \\
0.15 & $0.262 \pm 0.003^{*}$ \\
0.2 & $0.092 \pm 0.000^{*}$
\end{tabular}

Growth rates $\left(\mathrm{d}^{-1}\right)$ obtained in cultures of $C$. moewusii exposed to different paraquat concentrations after $48 \mathrm{~h}$ of exposure. Data are given as mean values of replicate cultures \pm standard errors of the means. Significant differences with respect to control at a level of significance of $0.05(p<0.05)$ are

The most common parameter used in toxicity assays is the $\mathrm{EC}_{50}$, i.e. the concentration of the tested substance that decreases the growth rate by $50 \%$. $\mathrm{EC}_{50}$ value after $48 \mathrm{~h}$ of herbicide 
exposure were obtained by graphic interpolation from concentration-response curves, being the estimated value $0.13 \mu \mathrm{M}(33.4 \mu \mathrm{g} \mathrm{L}-1)$ for the present work.

\subsection{Dry weight and elemental composition}

Cellular dry weight showed a significant $(p<0.05)$ increase in cultures exposed to paraquat concentrations of $0.1 \mu \mathrm{M}$ or higher respect to control cultures, reaching a maximum value in those exposed to the highest paraquat concentration $(0.2 \mu \mathrm{M})$; in these cultures cellular dry weight was nearly twice the value obtained for control cells ( Table 2).

Table 2.

Cellular dry weight (ng cell-1), carbon and nitrogen proportions, and carbon/nitrogen ratio obtained from cultures of $C$. moewusii used as inoculum and cultures exposed to different paraquat concentrations during $48 \mathrm{~h}$. Data are given as mean values of four replicates (two determinations for each duplicate culture) \pm standard deviation of the means. Significant differences with respect to control at a level of significance of $0.05(p<0.05)$ are represented by an asterisk $\left(^{*}\right)$.

\begin{tabular}{|c|c|c|c|c|}
\hline $\begin{array}{l}\text { Paraquat } \\
\text { concentration }(\mu \mathrm{M})\end{array}$ & $\begin{array}{l}\text { Dry weight } \\
\left(\text { ng cell }^{-1}\right)\end{array}$ & $\% \mathrm{C}$ & $\% \mathrm{~N}$ & $\mathrm{C} / \mathrm{N}$ \\
\hline Inoculum & $0.114 \pm 0.003$ & $38.384 \pm 0.083$ & $7.970 \pm 0.081$ & $4.817 \pm 0.060$ \\
\hline Control & $0.101 \pm 0.000$ & $38.652 \pm 0.374$ & $7.826 \pm 0.019$ & $4.940 \pm 0.036$ \\
\hline 0.05 & $0.112 \pm 0.004$ & $38.393 \pm 0.408$ & $7.721 \pm 0.057$ & $4.972 \pm 0.017$ \\
\hline 0.1 & $0.124 \pm 0.002^{*}$ & $37.880 \pm 0.351$ & $7.507 \pm 0.001^{*}$ & $5.046 \pm 0.046$ \\
\hline 0.15 & $0.154 \pm 0.001^{*}$ & $38.877 \pm 0.439$ & $6.976 \pm 0.146^{*}$ & $5.574 \pm 0.054^{*}$ \\
\hline 0.2 & $0.195 \pm 0.011^{*}$ & $39.367 \pm 0.140$ & $6.840 \pm 0.103^{*}$ & $5.758 \pm 0.107^{*}$ \\
\hline
\end{tabular}

No significant differences were observed for the percentage of carbon in dry biomass for all conditions assayed, whereas nitrogen percentage in dry biomass determined after $48 \mathrm{~h}$ decreases as paraquat concentration increases (Table 2). Then, the $\mathrm{C} / \mathrm{N}$ ratio increased significantly $(p<0.05)$ in cultures exposed to paraquat concentrations of 0.15 and $0.2 \mu \mathrm{M}$ in comparison with the ratio obtained in control cultures ( Table 2).

\subsection{Biochemical composition}

After $48 \mathrm{~h}$ of paraquat exposure, cellular chlorophyll a content was significantly $(p<0.05)$ increased respect to control cultures in $C$. moewusii cells exposed to concentrations above $0.05 \mu \mathrm{M}$ 


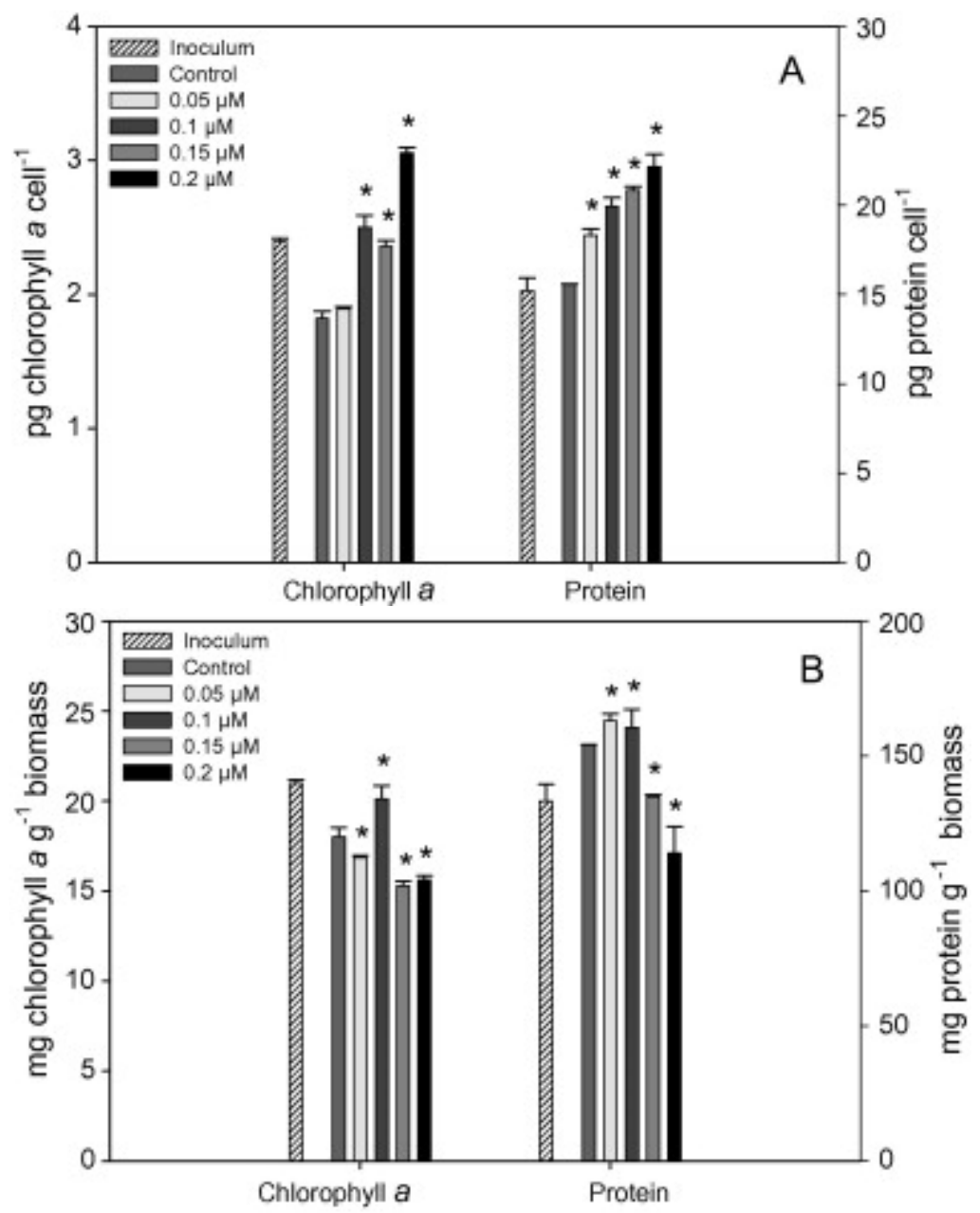

Fig. 1.

Chlorophyll $a$ and protein content, per cell (A) and per gram of dry biomass (B), obtained from cultures of $C$. moewusii used as inoculum and cultures exposed to different paraquat concentrations during $48 \mathrm{~h}$. Data are given as mean values of four replicates (two determinations for each duplicate culture) \pm standard deviation of the means. Significant differences with respect to control at a level of significance of $0.05(p<0.05)$ are represented by an asterisk $(*)$.

However, these differences observed for cell composition can be interpreted in a different manner if these data are expressed as a function of the cell biomass (Fig. 1B). Then, the concentration of chlorophyll per gram of dry biomass after $48 \mathrm{~h}$ decreases for all cultures respect to the value recorded for the inoculum $(0 \mathrm{~h})$; the highest paraquat concentrations assayed provoked a significant $(p<0.05)$ decrease of this parameter respect to control after $48 \mathrm{~h}$. Regarding the protein content, cultures with paraquat concentrations below $0.15 \mu \mathrm{M}$, including control cultures, showed an increase in their protein proportion of dry biomass after $48 \mathrm{~h}$ respect to the inoculum $(0 \mathrm{~h})$; at this time, cultures exposed to the highest paraquat concentrations assayed presented a significant $(p<0.05)$ decrease in this parameter respect to control ( Fig. 1B).

\subsection{Nitrate reductase and nitrite reductase activities}


Microalgal cultures exposed to paraquat concentrations above $0.05 \mu \mathrm{M}$ during $48 \mathrm{~h}$ showed a significantly $(p<0.05)$ reduced nitrate reductase activity in comparison with the control cultures (37.170 $\mathrm{U} \mathrm{g}^{-1}$ protein), so that nitrate reductase activity decreased as paraquat concentration increased in culture, being 10 times lower in cultures exposed to $0.2 \mu \mathrm{M}$; however, cultures exposed to $0.05 \mu \mathrm{M}$ showed a significantly $(p<0.05)$ higher nitrate reductase activity (45.186 $\mathrm{U} \mathrm{g}^{-1}$ protein) in comparison with control ( Fig. 2).

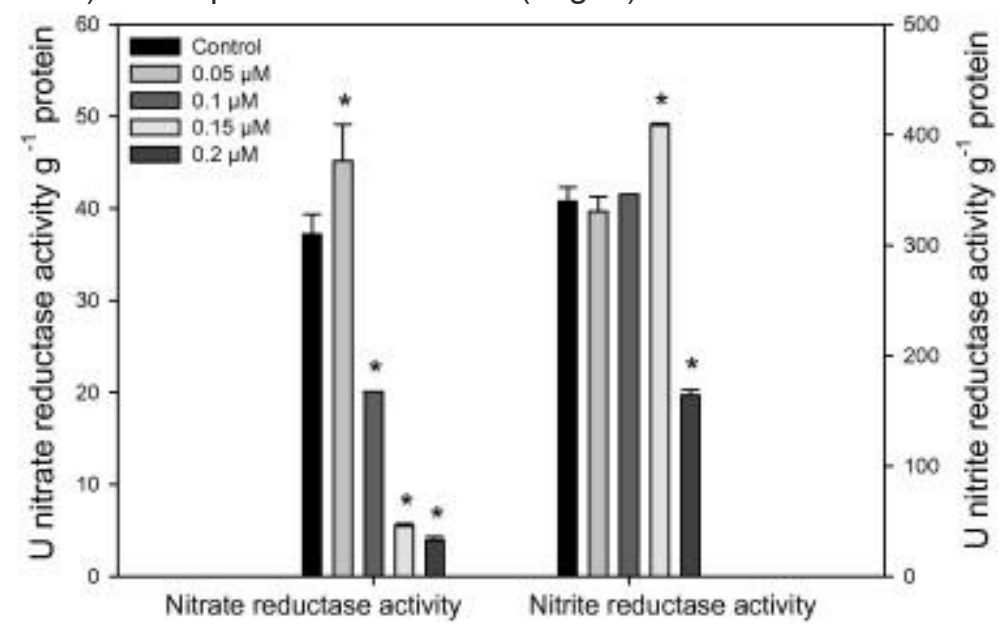

Fig. 2.

Nitrate reductase and nitrite reductase activity ( $\mathrm{U} \mathrm{g}$-1 protein) obtained from cultures of $C$. moewusii exposed to different paraquat concentrations, after $48 \mathrm{~h}$ of exposure. Data are given as mean values of six replicates (three determinations for each duplicate culture) \pm standard deviation of the means. Significant differences with respect to control at a level of significance of $0.05(p<0.05)$ are represented by an asterisk $\left(^{*}\right)$.

Cultures exposed to $0.15 \mu \mathrm{M}$ of paraquat showed a nitrite reductase activity significantly $(p<0.05)$ increased $\left(408.820 \mathrm{U} \mathrm{g}^{-1}\right.$ protein) in comparison with control cultures $\left(339.738 \mathrm{U} \mathrm{g}^{-}\right.$ ${ }^{1}$ protein), while cultures exposed to the highest paraquat concentration assayed showed a significant $(p<0.05)$ decrease in this enzymatic activity ( Fig. 2).

\section{Discussion}

Obtained results showed a decrease of the growth rate of $C$. moewusii when is exposed to paraquat concentrations above $0.05 \mu \mathrm{M}$ ( Table 1), as was observed on other freshwater green microalga,Scenedesmus quadricaudaBerb 614, exposed to paraquat concentrations of $0.02 \mathrm{mg} \mathrm{L}^{-1}$ or higher ( Wong, 2000). In the same way, adverse effects of paraquat on microalgal growth has also been observed onChlorella vulgaris, Pseudokirchneriella subcapitata and Pandorina morum, although with different sensitivities to the herbicide ( Oliveira et al., 2007).

Stimulation effects are often recorded in algal bioassays with different species and pesticides (Haglund, 1997, Franqueira et al., 1999, Wong, 2000, Rioboo et al., 2002 and Yoshida et al., 2003). The stimulation of growth observed at the lowest paraquat concentration assayed (Table 1) may be an attempt of algal cells to adapt to and resist the negative effect of herbicides. Some reports suggested that microalgal growth stimulation observed in the presence of certain 
concentrations of some herbicides, such as glyphosate, may have resulted from its use as carbon or nitrogen source for algal growth (Malik et al., 1989, Marsalek and Rojickova, 1996 and Wong, 2000).

$\mathrm{EC}_{50}$ values for the reduction of growth of Scenedesmus dimorphus and Ankistrodesmus falcatus were 39.8 and $93.3 \mu \mathrm{g} \mathrm{L}^{-1}$ ( Ibrahim, 1990), respectively, so that it was observed that $C$. moewusii is more sensitive to this herbicide than those microalgae. Investigations using different algal species as tests organisms have shown that algae vary greatly in their responses to contaminants, and this differential sensitivity could lead to changes in the structures of the biological communities ( Ma et al., 2006).

The observed increase in cellular dry weight may be related to the growth inhibition observed in cultures exposed to high paraquat concentrations. Photosynthesis-inhibiting herbicides may alter the overall bioenergetic status of the organism (Wilson et al., 2000), leading to the uncoupling of cell growth and reproductive processes, as reflected in the increase in the dry weight. This effect is in accordance with other investigations where increases in cell volume in different microalgae exposed to high concentrations of several contaminants were observed (Cid et al., 1996, Franqueira et al., 2000, Rioboo et al., 2002 and Calderón and Serpa, 2003), and might explain the increases observed in cellular chlorophyll and protein content. The increase of the cellular content of chlorophyll or protein (Fig. 1A) was therefore a consequence of a cell volume increase, represented by the observed increase in the dry weight (Table 2).

Changes of biochemical composition induced by exposure to high herbicide concentrations were observed previously (Franqueira et al., 1999, Rioboo et al., 2002 and González-Barreiro et al., 2004). Paraquat induces its toxic action via oxidative stress-mediated mechanisms. Hence, it has been indicated that this herbicide causes an oxidative degradation of chlorophyll (Kirtikara and Talbot, 1996), which can explain the significant reduction of chlorophyll content per gram of dry biomass in $C$. moewusii exposed to the highest paraquat assayed in the present study ( Fig. 1B). This loss of chlorophyll was clearer after $96 \mathrm{~h}$ of paraquat exposure (data not shown).

Obtained results in the present study agree with those observed by Laws and Chalup (1991), who reported that the $\mathrm{C} / \mathrm{N}$ ratio is a parameter inversely correlated with the growth rate. The increase observed in the $\mathrm{C} / \mathrm{N}$ ratio in cultures exposed to high paraquat concentrations was fundamentally due to a decrease in nitrogen content in the dry biomass, while the carbon content remained constant for all paraquat concentrations assayed (Table 2). This unexpected result leads us to analyse the effects of this herbicide on enzymes involved in nitrogen assimilation.

In higher plants and algae, nitrate is the predominant form of assimilated nitrogen and must be reduced to nitrite and subsequently to ammonium by nitrate reductase and nitrite reductase, respectively (Granum et al., 2002 and Kato et al., 2006).

Results obtained in this work appear to point to the fact that nitrate reductase activity is more sensitive to paraquat than nitrite reductase, since only after $48 \mathrm{~h}$ of exposure to paraquat concentrations of $0.1 \mu \mathrm{M}$ or higher a significant decrease in that enzymatic activity was observed, while it takes an herbicide concentration twice that to significantly reduce nitrite 
reductase activity, which was even stimulated in those cultures exposed to $0.15 \mu \mathrm{M}$ of paraquat. These negative effects on enzymes involved in nitrogen assimilation agree with the results showing a significant decrease in the proportion of proteins of the dry biomass in cultures exposed to the highest paraquat concentrations assayed (Fig. 1B). The increase recorded in this parameter in cultures exposed to lower herbicide concentrations could be related with a detoxification mechanism (Kruglov, 1970).

Nitrate reductase activity inhibition by paraquat has already been observed by Kenis et al. (1992) who concluded that this effect depends on the enhanced production of free radicals induced by the herbicide.

Nitrite reduction is functionally associated with the photosynthetic electron transport, so that it stands to reason that photosynthetic herbicides, such as paraquat, interfere with the assimilation of nitrite (Neyra and Hageman, 1974).

On the other hand, a stimulation effect of these enzymatic activities was also observed in cultures exposed to lower paraquat concentrations. Several studies have reported stimulation effects in enzymatic activities involved in nitrogen metabolism induced by different moderate stress sources: high $\mathrm{CO}_{2}$ concentrations (Agüera et al., 2006), photosynthetic inhibitor herbicides (Wu et al., 1971, Singh et al., 1998 and Nemat Alla et al., 2008) and toxic metals (Domínguez et al., 2003 and Sharma and Dubey, 2005).

Nitrogen assimilation and carbon fixation are highly coordinated in unicellular algae (Huppe and Turpin, 1994 and Giordano et al., 2005);

so that an herbicide that finally should interferes in the photosynthetic carbon fixation goes on to also interfere in enzymatic activities involved in nitrogen assimilation. However, results obtained in the present study seem to indicate that negative effects of paraquat on nitrogen metabolism are not a consequence of alterations in the carbon fixation, so that those became patently clear while alterations in carbon content were not observed.

Results obtained in the present work demonstrated adverse effects of paraquat upon a common freshwater green alga, thus the application of this herbicide for weed control in agricultural practices must be done with extreme caution, so that any disturbance affecting algae with similar and higher sensitivity will have severe repercussions on higher trophic levels and on elemental biogeochemical cycles.

\section{Acknowledgements}

This work was carried out with the financial support of the Spanish Ministerio de Educación y Ciencia (CGL 2004/02037 BOS). R.P. acknowledges a F.P.U. fellowship from the Spanish Ministerio de Educación y Ciencia. Authors want to express their gratitude to the anonymous reviewers of this paper who have contributed to its improvement.

\section{References}

E. Agüera, D. Ruano, P. Cabello, P. de la Haba 
Impact of atmospheric $\mathrm{CO} 2$ on growth, photosynthesis and nitrogen metabolism in cucumber (Cucumis sativus L.) plants

J. Plant Physiol., 163 (2006), pp. 809-817

L.L. Amado, C.D.E. Rosa, A.M. Leite, L. Moraes, W.V. Pires, G.L.L. Pinho, C.M.G. Martins, R.B. Robaldo, L.E.M. Nery, J.M. Monserrat, A. Bianchini, P.E. Martínez, L.A. Gericitano

Biomarkers in croakers Micropogonias furnieri (Teleostei: Sciaenidae) from polluted and non-polluted areas from the Patos Lagoon estuary (Southern Brazil): evidences of genotoxic and immunological effects Mar. Pollut. Bull., 52 (2006), pp. 199-206

M.R. Arkoosh, E. Casillas, E. Clemons, A.N. Kagley, R. Olson, P. Reno, J.E. Stein

Effect of pollution on fish diseases: potential impacts on salmonid populations

J. Aquat. Anim. Health, 10 (1998), pp. 182-190

J.L. Barea, J. Cárdenas

The nitrate-reducing enzyme system of Chlamydomonas reinhardtii

Arch. Microbiol., 105 (1975), pp. 21-25

\section{J.A. Berges, P.J. Harrison}

Nitrate reductase activity quantitatively predicts the rate of nitrate incorporation under steady state light limitation: a revised assay and characterization of the enzyme in three species of marine phytoplankton Limnol. Oceanogr., 40 (1995), pp. 82-93

\section{M.M. Bradford}

A rapid and sensitive method for the quantitation of microgram quantities of protein utilizing the principle of protein-dye binding

Anal. Biochem., 72 (1976), pp. 248-254

T.E. Brown, F.L. Richardson, M.L. Vaughn

Development of red pigmentation in Chlorococcum wimmeri (Chlorophyta: Chlorococcales)

Phycologia, 6 (1967), pp. 167-184

A. Calderón, R.F. Serpa

Efectos del paraquat sobre el crecimiento y la morfología de la microalga Dunaliella tertiolecta

Ecología Aplicada, 2 (2003), pp. 99-102

\section{A. Cid, P. Fidalgo, C. Herrero, J. Abalde}

Toxic action of copper on the membrane system of a marine diatom measured by flow cytometry

Cytometry, 25 (1996), pp. 32-36

M.E. De Lorenzo, L.A. Taylor, S.A. Lund, P.L. Pennington, E. Strozier D., M.H. Fulton

Toxicity and bioconcentration potential of the agricultural pesticide endosulfan in phytoplankton and zooplankton

Arch. Environ. Contam. Toxicol., 42 (2002), pp. 173-181 
J.W. Deneer

Toxicity of mixtures of pesticides in aquatic systems

Pest. Manage. Sci., 56 (2000), pp. 516-520

M.J. Domínguez, F. Gutiérrez, R. León, C. Vílchez, J.M. Vega, J. Vigara

Cadmium increases the activity levels of glutamate dehydrogenase and cysteine synthase in Chlamydomonas reinhardtii

Plant Physiol. Biochem., 41 (2003), pp. 828-832

M. Fatima, S.N.M. Mandiki, J. Douxfils, F. Silvestre, P. Coppe, P. Kestemont

Combined effects of herbicides on biomarkers reflecting immune-endocrine interactions in goldfish Immune and antioxidant effects. Aquat. Toxicol., 81 (2007), pp. 159-167

D. Franqueira, A. Cid, E. Torres, M. Orosa, C. Herrero

A comparison of the relative sensitivity of structural and functional cellular responses in the alga Chlamydomonas eugametos exposed to the herbicide paraquat

Arch. Environ. Contam. Toxicol., 36 (1999), pp. 264-269

D. Franqueira, M. Orosa, E. Torres, C. Herrero, A. Cid

Potential use of flow cytometry in toxicity studies with microalgae

Sci. Total Environ., 247 (2000), pp. 119-126

G. Ganf, S. Stone, R. Oliver

Use of protein to carbohydrate ratios to analyse for nutrient deficiency in phytoplankton

Aust. J. Mar. Freshwater Res., 37 (1986), pp. 183-197

M. Giordano, Y. Chen, M. Koblizek, P.G. Falkowski

Regulation of nitrate reductase in Chlamydomonas reinhardtii by the redox state of the plastoquinone pool Eur. J. Phycol., 40 (2005), pp. 345-352

O. González-Barreiro, C. Rioboo, A. Cid, C. Herrero

Atrazine-induced chlorosis in Synechococcus elongatus cells

Arch. Environ. Contam. Toxicol., 46 (2004), pp. 301-307

S. Granum, S. Kirkvold, S.M. Myklestad

Cellular and extracellular production of carbohydrates and amino acids by the marine diatom Skeletonema costatum: diel variations and effects of $\mathrm{N}$ depletion

Mar. Ecol. Prog. Ser., 242 (2002)

K. Haglund

The use of algae in aquatic toxicity assessment

F.E. Round, D.J. Chapman (Eds.), Progress in Phycological Research, Biopress Ltd., Bristol (England) (1997), pp. 181-212 
H.C. Huppe, D.H. Turpin

Integration of carbon and nitrogen metabolism in plant and algal cells

Ann. Rev. Plant Physiol. Plant Mol. Biol., 45 (1994), pp. 577-607

M. Ibáñez, Y. Picó, J. Mañes

Influence of organic matter and surfactans on solid-phase extraction of diquat, paraquat and difenzopuat from waters

J. Chromatogr. A, 727 (1996), pp. 245-252

E.A. Ibrahim

The influence of the herbicide paraquat "gramoxon" on growth and metabolic activity of three chlorophytes Water Air Soil Pollut., 51 (1990), pp. 89-93

S.W. Jeffrey, G.F. Humphrey

New spectrophotometric equations for determining chlorophylls a, b, c1 and c2 in higher plants, algae and natural phytoplankton

Biochem. Physiol. Pflanz., 167 (1975), pp. 191-194

Y. Kato, S. Ueno, N. Imamura

Studies on the nitrogen utilization of endosymbiotic algae isolated from Japanese Paramecium bursaria Plant Sci., 170 (2006), pp. 481-486

J.D. Kenis, S.T. Silvente, J.D. Morlans, C.M. Luna

Glycolate-, xanthine- and paraquat-mediated inhibition of nitrate reductase in detached oat leaves Plant Cell Physiol., 33 (1992), pp. 315-320

K. Kirtikara, D. Talbot

Alteration in protein accumulation, gene expression and ascorbate-glutathione pathway in tomato (Lycopersicon esculentum) under paraquat and ozone stress

J. Plant Physiol., 148 (1996), pp. 752-760

Y.V.a.E.I.P. Kruglov

Detoxification of simazine by microscope algae

Mikrobiologiya, 39 (1970), pp. 157-160

E.A. Laws, M.S. Chalup

A microalgal growth model

Limnol. Oceanogr., 35 (1991), pp. 597-608

J. Ma, L. Xu, S. Wang, R. Zheng, S. Jin, S. Huang, Y. Huang

Toxicity of 40 herbicides to the green alga Chlorella vulgaris

Ecotoxicol. Environ. Safety, 51 (2002), pp. 128-132 
J. Ma, S. Wang, P. Wang, L. Ma, X. Chen, R. Xu

Toxicity assessment of 40 herbicides to the green alga Raphidocelis subcapitata

Ecotoxicol. Environ. Safety, 63 (2006), pp. 456-462

J. Malik, G. Barry, G. Kishore

The herbicide glyphosate

Biofactor, 2 (1989), pp. 17-25

B. Marsalek, R. Rojickova

Stress factors enhancing production of algal exhudates: a potential self-protective mechanism?

J. Biosci. C, 51 (1996), pp. 646-650

M.M. Nemat Alla, A.M. Badawi, N.M. Hassan, Z.M. El-Bastawisy, E.G. Badran

Effect of metribuzin, butachlor and chlorimuron-ethyl on amino acid and protein formation in wheat and maize seedlings

Pest. Biochem. Physiol., 90 (2008), pp. 8-18

C.A. Neyra, R.H. Hageman

Dependence of nitrite reduction on electron transport in chloroplast

Plant Physiol., 54 (1974), pp. 480-483

J.B. Oliveira, A.M.M. Goncalves, F. Goncalves, M.J. Pereira

Growth inhibition of algae exposed to paraquat

Fresen. Environ. Bull., 16 (2007), pp. 621-625

D. Pimentel

Amounts of pesticides reaching target pests: environmental impacts and ethics

J. Agric. Environ. Ethics, 8 (1995), pp. 17-29

C. Rioboo, O. González, C. Herrero, A. Cid

Physiological response of freshwater microalga (Chlorella vulgaris) to triazine and phenylurea herbicides Aquat. Toxicol., 59 (2002), pp. 225-235

C. Rioboo, R. Prado, C. Herrero, A. Cid

Population growth study of the rotifer Brachionus sp. fed with triazine-exposed microalgae

Aquat. Toxicol., 83 (2007), pp. 247-253

P. Sharma, R.S. Dubey

Modulation of nitrate reductase activity in rice seedlings under aluminium toxicity and water stress: role of osmolytes as enzyme protectant

J. Plant Physiol., 162 (2005), pp. 854-864

P. Singh, S. Prakash, H.L. Grover

Effect of 2,4-D on the nitrate assimilation process in cowpea shoot 
Pest. Biochem. Physiol., 61 (1998), pp. 15-20

F.D. Snell, C.T. Snell

Colorimetric Methods of Analysis

Van Nostrand, New York (1949)

A. Tanguy, I. Boutet, J. Laroche, D. Moraga

Molecular identification and expression study of differentially regulated genes in the Pacific oyster Crassostrea gigas in response to pesticide exposure

FBS J., 359 (2005), pp. 90-100

S.D. Utting

Influence of nitrogen availability on the biochemical composition of three unicellular marine algae of commercial importance

Aquacult. Eng., 4 (1985), pp. 175-190

P.C. Wilson, T. Whitwell, S.J. Klaine

Phytotoxicity, uptake, and distribution of 14C-simazine in Acorus gramenius and Pontederia cordata

Weed Sci., 48 (2000), pp. 701-709

P.K. Wong

Effects of 2, 4-D, glyphosate and paraquat on growth, photosynthesis and chlorophyll-a synthesis of Scenedesmus quadricauda Berb 614

Chemosphere, 41 (2000), pp. 177-182

M.T. Wu, B. Singh, D.K. Salunkhe

Influence of s-triazines on some enzymes of carbohydrates and nitrogen metabolism in leaves of pea (Pisum sativum L.) and sweet corn (Zea mays L.)

Plant Physiol., 48 (1971), pp. 517-520

K. Yoshida, E. Igarashi, M. Mukai, K. Hirata, K. Miyamoto

Induction of tolerance to oxidative stress in the green alga, Chlamydomonas reinhardtii, by abscisic acid Plant Cell Environ., 26 (2003), pp. 451-457

Corresponding author. Tel.: +34 981 167000; fax: +34 981167065.

Copyright (C) 2009 Elsevier Ltd. All rights reserved. 